\title{
Fuel Cell designing with optimal high speed air compressor
}

\author{
Nabeel Ahsan ${ }^{1}$, Mahrukh Mehmood ${ }^{2}$, Asad A. Zaidi ${ }^{3 凶}$ \\ 1 School of Energy and Power Engineering, Xi'an Jiaotong University, Xi'an, PR China \\ 2 University of Sindh, Jamshoro, Sindh, Pakistan \\ 3 Department of Engineering Sciences, PN Engineering College, National University of Sciences and Technology, Karachi, Pakistan
}

\author{
Received October 20, 2020 \\ Revised March 7, 2021 \\ Accepted April 24, 2021 \\ Published online: April 26, 2021 \\ Keywords \\ Fuel cell stack \\ Proton exchange membrane \\ Air supply \\ Turbo-compressor \\ Current load \\ Performance
}

\begin{abstract}
This paper discusses different air management technologies for fuel cell systems. Two different types of compressors are analyzed for Proton-exchange membrane fuel cells (PEMFC). Some important criteria are analyzed thoroughly for the selection of turbo compressor among different types of compressors illustrated with the help of matrix representations. The impacts of various input parameters for Fuel Cell (FC) are also explained thoroughly. Later the numerical modeling of an automobile fuel cell system using a high speed turbo-compressor for air supply is explained. The numerical model incorporates the important input parameters related with air and hydrogen. It also performed energy and mass balances across different components such as pump, fan, heat-exchanger, air compressor and also keeps in consideration the pressure drop across the flow pipes and various mechanical parts. The model is solved to obtain the characteristics of the FC system at different operating conditions. Therefore, it can be concluded that the high speed turbo compressor with a turbo-expander can have significant effects on the overall system power and efficiency.
\end{abstract}

(C) 2021 The authors. Published by Alwaha Scientific Publishing Services, ASPS. This is an open access article under the CC BY license.

\section{Introduction}

The world is facing a significant energy crisis due to increased energy demand (Malik et al., 2020; Mehdi et al., 2019). The conventional sources alone cannot fulfill this ever-increasing demand for energy because conventional energy sources are mostly nonrenewable energy sources that tend to deplete with time (Mushtaq et al., 2016). So, it is a fact that there is a great need for energy sources that do not deplete and damage the environment (Faiz Ahmed et al., 2016; Mondial et al., 2013). Renewable energy sources are on the other hand ecofriendly. One such source for energy catering energy crisis is fuel cell (Akinyele et al., 2020).
Fuel cell technology is more than a century old. Many great scientists and researchers worked to develop the perfect fuel cell (FC) and they also succeeded to some extent (AlBaghdadi, 2017). However, apart from the fuel cell itself there are many important factor and design parameters in the shape of primary and secondary components of the whole FC system. Still there is a vacuum for further research in the area of air and fuel management system (Gimba et al., 2016).

Air compressor is one of the key components in a FC system. It plays a vital role in the overall system performance and efficiency (Bethoux, 2020; Weyers and Bocklisch, 2018). It is basically a machine in which a specific fluid is compressed with the help of an impeller.

\footnotetext{
${ }^{\square}$ Corresponding author. E-mail address: asadali@pnec.nust.edu.pk 
The compressor can have single stage or multi-stages for larger proportions of compression (Yu et al., 2015; Zhao et al., 2012). The next important component inside the compressor is the diffuser. In the flow path downstream of the impeller, the conversion of remaining kinetic energy (high velocity) of the gas into pressure is carried out by the diffuser. The last component is the volute which provides a smooth swirl path for the pressurized fluid to exit the compressor (Ahsan et al., 2019).

This study investigates the development of a preliminary design method for turbo compressors (Pakle and Jiang, 2018). The design process begins with the aerodynamic analysis of the preliminary design and its dependence on the input parameters. Six manufacturing factors are considered related to the compressor pre-designing process (Sugawara et al., 2016). The minimum and maximum input parameter values are taken into consideration. The limits of the diffusion factor were also considered.

\section{Evaluation Model for Air Compressor}

The type of fuel cell used in the system is the Proton Exchange Membrane Fuel Cell (PEMFC), due to the obvious reason that this type of FC can be easily stacked together to produce a power output to run an automobile and has an operating temperature which is optimum for an automobile (Pukrushpan, 2003). The fuel cell stack (FCS) size is modeled to produce 132 horse power $(98.5 \mathrm{~kW})$ which is equal to the horse power of the world renowned medium sized car i.e. Toyota Corolla. This size of a FC system would be sufficient to power an average sized vehicle. The FCS is made up of 346 individual FCs and has a total area of $1117 \mathrm{~cm}^{2}$ (Kulp, 2001).

In order to power a medium size automobile, a FCS needs to be integrated with other components to form a FC system. The diagram in Figure 1 shows the minimal components required for a FC system. The FCS requires four flow systems:
a) Hydrogen supply system to the anode
b) Air supply system to the cathode
c) Water separator to separate the air and water
d) Humidifier to humidify the hydrogen and the air flows

The reaction rate is significantly improved by high air pressure, and thus, the FCS efficiency and power density. Therefore, a compressor is required to increase the pressure of air to the optimum pressure level. As a result of high temperature of the air leaving the compressor a humidifier is used to add vapor into the air flow, as illustrated in Fig. 1, in order to cater the dehydration of the membrane. The air is saturated as it leaves the FC. For an automotive FC system, a water separator is necessary to recover the excess water. On the anode side, hydrogen is supplied from the storage tank. A valve is used to control the flow rate of hydrogen after frequently checking the temperature and pressure of the hydrogen gas via the temperature and pressure sensors. Since the temperature of the stack should be controlled below $100^{\circ} \mathrm{C}$ to protect the membrane from any damage, excessive heat released in the $\mathrm{FC}$ reaction is extracted and supplied back to the humidifier/heat exchanger to overcome the drop in air temperature due to frictional losses.

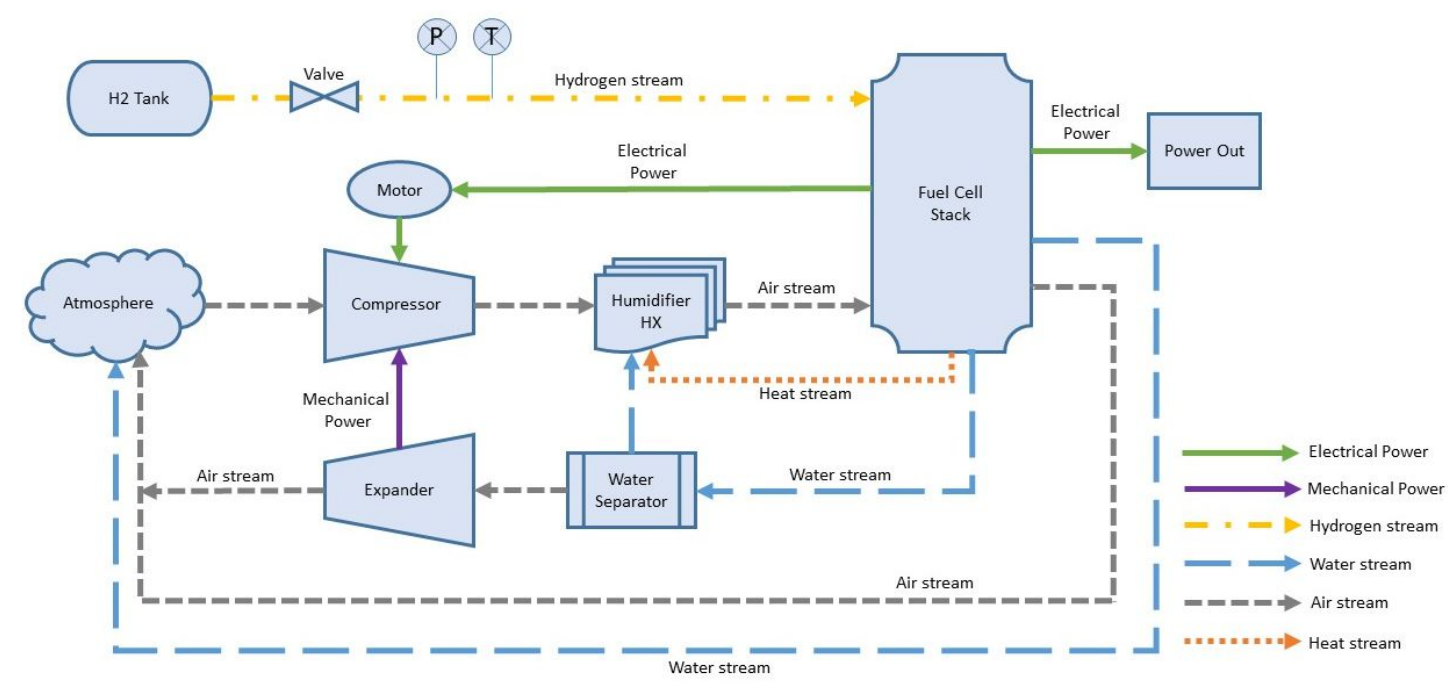

Fig. 1 FC system flow diagram. 
As a result of cell reaction, heterogeneous air and water stream coming out of the FCs is passed through the water separator. The water separator separates the air stream from the mixed stream. Water is channeled to the humidifier for humidification of incoming air, while the air stream is passed into the expander which converts the kinetic energy of air stream into mechanical energy. The expander and compressor both are joined by a single shaft, so when the expander rotates the mechanical energy is transferred to the compressor also which also starts to rotate. In this way, the waste air stream is utilized to do compressor work. However, the major portion of compressor work is done by the electrical energy which is supplied by the FCS. Only a small portion of the electrical energy produced by the FCS is used by the compressor motor while the rest is used by the vehicle drive train (Ahsan et al., 2019). In order to achieve some fundamental goal in the simulation of system some assumptions are taken into consideration.

a) Specific heats are assumed to be constant and ideal gases are assumed.

b) No change in the air and fuel properties within the operating range of the system.

c) No pressure drops in the flow channel except across the FC and the expander.

d) No flow resistance in the whole system.

The properties and design points of important mechanical components which are turbo-compressor and expander used in the model are listed in Table 1.

The polarization curve is an important representation of FC performance. It reveals the output voltage of the FC for a given current density. These curves are usually obtained with a galvanostat, which draws a fixed current from the FC and measures the output voltage. Fig. 2, shows the typical polarization curve of proton exchange membrane FC (Wilberforce and Olabi, 2020).

\section{Selection of Suitable Compressor Type}

Generally, air compressors are categorized into the following two different classes based upon the operation principle.

a) Positive displacement

b) Aerodynamics

Turbochargers belong to the aerodynamic compressors, while other compressors (or mechanical paddles) belong to the volumetric compressors (Robison and Beaty, 1992),

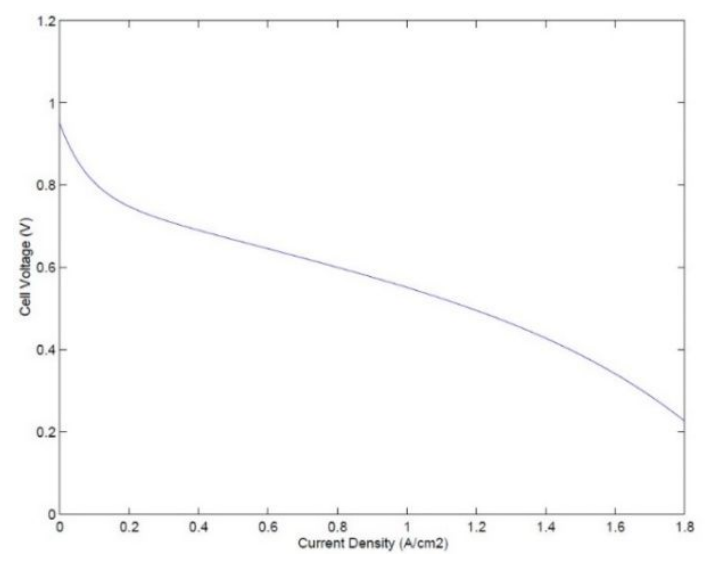

Fig. 2 Typical polarization curve

Table 1 Properties of Compressor and Expander

\begin{tabular}{lccc}
\hline Specifications & Compressor & Expander & Units \\
\hline Design type & Centrifugal & Centrifugal & \\
Efficiency & 88.0 & 81.0 & $\%$ \\
Temperature of air at inlet & 298 & 358 & $\mathrm{~K}$ \\
Temperature of air at outlet & 363 & 298 & $\mathrm{~K}$ \\
\hline
\end{tabular}

the important criteria for choosing a compression system suitable for the FCV application listed and compared in the form of weighting and rating matrix.

\subsection{Weighting and Rating Matrices}

The weighting and rating matrices are a critical element in evaluating the various concepts and choosing the most suitable among them. Firstly, selection of the important design features which are to be included in the weighted matrix is carried out. Secondly, those factors are compared with each other. All rows and columns were compared with each other. The factor which has greater significance compared to its counter-part then digit ' 1 ' is entered at the respective position in the matrix. Likewise, the factor which has less significance compared to its counter-part then digit ' 0 ' is entered at the respective position. After that scores are calculated and allocated to the different factors according to their significance. Afterwards, rating matrix is formulated. Similar to the above matrix, several factors were compared according to their usefulness and score between 0,1 and 2, are allocated to each of them. Score ' 2 ' shows that the factor meets the requirement completely, while score ' 0 ' shows that the factor does not meet the requirement at all. At last, the concept with the highest cumulative score is considered the best possible concept. This practice is very subjective as an apparent strong feature could distort the results. The design features which have been taken into consideration are discussed below; 


\subsubsection{Efficiency}

First and one of the most significant design feature selected is efficiency because the fundamental idea of the whole project is to improve the efficiency of the individual compressor by optimizing the different input parameters. In order to get multiplied output in terms of efficiency of the whole Fuel Cell System.

\subsubsection{Manufacturing Cost}

Second design feature is the manufacturing cost of the compressor. Cost also plays an important role, when we need to focus on mass production. The compressor will be used by the automotive industry so the unit cost of the product has to be kept as low as possible in order to step into the market competition.

\subsubsection{Vibrations}

Third design feature is the vibrations produced during the operation. The more vibration compressor produces, means the whole system is jerky and noisy. As a result, the system is unstable and hence the performance of the vehicle is not up to the hill. However, vibration is not one of the most important factors because vibrations produced by the compressor can be damped by using other mechanical components to make the system stable.

\subsubsection{Mass Limitation}

Fourth design feature is the mass limitation. It can be considered as the most crucial factor in the selection strategy because all the mechanical and electrical components are installed very closely to each other. Therefore, availability of space for the installation of compressor is the major issue which has to be kept in mind before designing the compressor.

\subsubsection{Complexity}

Fifth design feature is the complexity of the compressor and ease of maintenance in case of failure. Design complexity is also an important feature but in case of rotating machinery, the design complexity cannot be overcome completely. Almost all the compressor types have a specific kind of design complexity and troublesome maintenance when a failure occurs.

\subsubsection{Safety}

Sixth design feature is the safety of the compressor. However, safety should be the first priority before designing a product but keeping in view the installation place and other safety components in the vehicle it can be over seen. This is because in case of explosion, the compressor parts would not come into contact with the people seating in the car. The car is equipped with many of the safety equipment for the protection of the driver.

\section{Air \& Fuel Input Parameters}

The most important and pre-designing step of a turbocompressor is defining the different air and fuel input parameters which will be analyzed and optimized to get the best results in the form of Fuel cell system's overall efficiency improvement (Wan et al., 2017). Some of the input parameters are following:
a) Pressure of air
b) Temperature of air
c) Humidity of air
d) Types of flow (laminar/turbulent) of air
e) Mass flow rate of air
f) Ratio of fuel and air

\subsection{Pressure}

Pressure of air coming out of the compressor and going into the FCS is the most significant parameter which affects the efficiency of the FC system. The pressure of air going into the compressor is not a matter of issue because the air going into the compressor is always at ambient pressure which is approximately equal to 1 bar. Therefore, there should be minimum pressure drop across the pipes and other components of the system. Too low air pressure will result in the lower efficiency of the system likewise too high pressure may damage the FCS.

\subsection{Temperature}

Temperature of air coming out of the compressor and going into the FCS is also one of the most significant parameter which affects the efficiency of the FC system (Shamim et al., 2015). The temperature of air going into the compressor is however a matter of issue because the air going into the compressor is always at ambient temperature which is assumed to be at $25^{\circ} \mathrm{C}$. But the inlet temperature is more fluctuating compared to the inlet pressure. The temperature may vary from -20 to $50^{\circ} \mathrm{C}$ from place to place at different seasons. Too low air temperature will result in the lower efficiency of the system likewise too high temperature may damage the fuel cell membrane.

\subsection{Humidity}

Humidity of air coming out of the compressor and going into the FCS is also another important parameter which 
affects the efficiency of the FC system. Similar to temperature, the humidity of air coming into the compressor can vary to large extends. It not only varies from season to season but can vary from nearby surroundings. For example, the humidity of air near the sea shore can be very high but as soon as we go to a desert the humidity of air can be extremely low. In order to overcome this issue a humidifier is used to between the compressor and FCS to keep the optimum level of humidity in the air when entering the fuel cell stack (Pischinger et al., 2001). As fuel cell itself produces water in the form of reaction products so there is no need of adding water from any external source. Controlling the optimum quantity of water within a PEMFC is necessary for proper operation. Excess of water will cause the cell to become flooded; likewise, shortage of water will cause the cell membrane to become dehydrated and may severely degrade cell performance.

\subsection{Other input parameters}

Other input parameters may also have a prominent impact on the FC performance and may prove of equal importance in increasing the overall efficiency of the FC system (Hoogers, 2002). Some of those parameters are type of air flow, for example the flow of air should be laminar of turbulent. The smoother the flow is the higher the diffusion of fluid through the membrane. Vice-versa, the higher the Reynold's number is (i.e. turbulent) the higher mass flow rate and hence the higher the rate of diffusion. Other parameter can be mass flow rate, continuity of low and the concentration ratio of the reactants. The ratio should be kept optimum in order to utilize the same amount of hydrogen for a longer period of time. The continuity of low can be described as the frequency of flow; it should be pulsating or continuous. If the flow will be continuous there are higher chances of some hydrogen molecules to expel out without taking part into the reaction. If the flow will be pulsating the voltage generated by the stack may experience a minor but rapid fluctuation.

\section{System Modelling}

The simulation is done by using the software MATLAB. The program is used to simulate the FC system with the turbo compressor (Yun and Joseph 1996) and gives system efficiencies and other output values such as pressure and mass flow operating lines to get the highest FC system efficiency.
The MATLAB model consists of seven sections and three programming loops as shown in Fig. 3. At the beginning of the model there are Several constant values to the system are used such as physical constants, compressor-specific constants, FC specific constants, and any user input values. Once the values are provided, the model starts to simulate accordingly and performs various iterations for every section in ascending order. Firstly, some initial calculations are performed to obtain the stack power, stack efficiency, stack voltage, mass flow rate of fuel required and mass flow rate of oxygen required and hence mass flow rate of air.

Then the program moves to compressor section and perform iterations on data gained from the compressor maps. Since the compressor characteristic values are normalized, in order to manipulate its size the maximum values for the compressor can be used (Ganesan, 2010). For the desired FC temperature and relative humidity all ambient conditions (inputs to the compressor) are specified. Several initial calculations have been carried out before the primary components of the FC system run in the program. These include the expected values for the maximum flow rates and the calculation of the compressor pressure. The equation for determining the power (in Watts) required by turbo compressor is the following:

$P_{\text {comp }}=\frac{\left(\left(\frac{\dot{m}_{\text {dry air }}}{M_{\text {air }}}+\frac{\dot{m}_{\text {vap }}}{M_{\text {vap }}}\right) R T \frac{k}{(k-1)}\left(\frac{P_{\text {out }}}{P_{\text {in }}}\right)^{(k-1) / k)}-1\right)}{\eta_{\text {comp }} \eta_{\text {motor }}}$

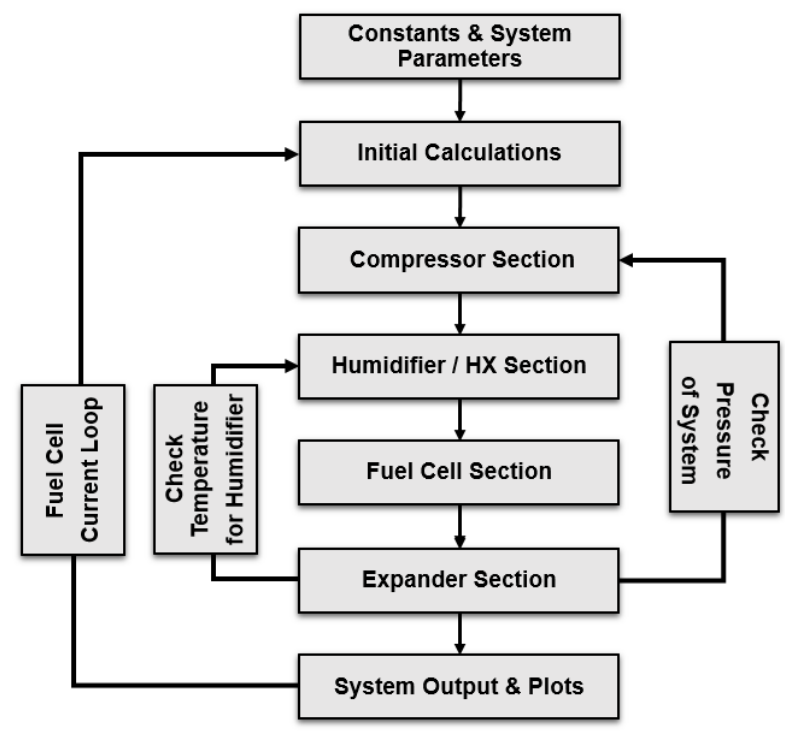

Fig. 3 MATLAB model flow chart. 
where $\mathrm{P}_{\text {comp }}$ is the power (W) consumed by the compressor, $\mathrm{T}$ is ambient air temperature $(\mathrm{K})$ and $\mathrm{k}$ is specific heat ratio. $\mathrm{P}_{\text {in }}$ andP $\mathrm{P}_{\text {out }}$ are inlet and outlet pressures (bar) respectively. $\dot{\mathrm{m}}_{\text {dry air }}$ and $\dot{\mathrm{m}}_{\text {vap }}$ are mass flow rates $(\mathrm{kg} / \mathrm{s})$ of air flowing. $\mathrm{R}$ is the universal gas constant $(\mathrm{J} / \mathrm{mol} \cdot \mathrm{K}) \mathrm{M}$ is the molecular mass, $\eta_{\text {comp }}$ and $\eta_{\text {motor }}$ are combined stages efficiencies of compressor and motor repectively. The model calculates power, speed, temperature and pressure rise inside the compressor.

Once the calculations are performed, the program enters the humidifier section and checks the humidity of air entering the fuel cell stack. If the humidity is low, then a message is sent to the humidifier section to further increase the humidity of air to get the optimum performance of stack.

After that, the program enters the most important section which is fuel cell stack. In this section several parameters are calculated while using different formulae. Temperature rise inside stack, pressure drop of air inside stack at exit point, stack power, water produced, stack voltage and stack efficiency are calculated based on data from the previous sections. The most important aspect of this section is the voltage equation, which also gives the polarization curve:

$$
\begin{aligned}
V_{f c} & =1.03-0.06 \log _{10}(J)-\left(1.12-0.0025 T_{o}\right) J \\
& +0.14 \log _{10}\left(P_{O 2}\right)+\left(T_{o}-333\right) \times 0.0004 \log _{10}(J)
\end{aligned}
$$

where; $V$ is cell voltage $(V), J$ is cell current density $\left(A / \mathrm{cm}^{2}\right), T_{0}$ is cell average temperature $(K)$ and $P_{O 2}$ is average partial pressure of oxygen in cell (bar.abs).

The above equation provides the voltage output of each FC based on the current load, temperature and oxygen levels available. FCS output such as efficiency and net power, are calculated in this section. Iterations are performed to keep the stack temperature below the critical temperature limit for the safe operation of stack.

Then the program enters the expander section and calculates the power produced by the expander by utilizing the excess compressed air coming out of the stack. In this section mass flow rate, air temperature and pressure are used from the stack section to calculate the above parameters for the system. If the results obtained from expander sections are not within the range of operational values, then the program again moves back to compressor section and humidifier section while using 'for loops'. The program again performs iterations on preceding sections and modifies the values to recheck the output results obtained at the expander sections.

Once the results obtained are within the operational range of system then the program moves into the last section where the results are obtained. All the important results of different sections and overall system are shown in the form of graphical representations; the results are plotted keeping the $x$-axis same. Current range has been kept limited because the system cannot exceed the too much current to prevent the system from any irreversible damage. There are several programming loops in the program such as current-loop, pressure-loop, and temperature-loop and simultaneously iterations are being performed by the model to obtain the refined results of the fuel cell system integrated with turbo compressor and expander.

\section{Results and Discussion}

\subsection{Performance evaluation of air compressor}

In the designing of highly efficient FC system, it is important to analyze the operating parameters and their consequences on the system performance. However, in practical scenario the operating parameters of a FC vehicle are constantly changing due to change in surrounding conditions.

These include ideal operating conditions (for highest expected efficiency), minimum mass flow operation and frequently changing ambient conditions, stack temperatures and stack pressures. Design parameters and characteristics of FC system are shown in Table 2 below.

Table 2 System parameters.

\begin{tabular}{lll}
\hline Specifications & Values & Units \\
\hline Design power & 98.5 & $\mathrm{~kW}$ \\
No. of cells & 346 & \\
Cell effective area & 1117 & $\mathrm{~cm}^{2}$ \\
Fan power & 0.412 & $\mathrm{~kW}$ \\
Pump power & 1.482 & $\mathrm{~kW}$ \\
Mass flow via pump & 5.19 & $\mathrm{~g} \cdot \mathrm{s}^{-1}$ \\
Max current load & 475 & $\mathrm{~A}$ \\
Min current load & 5 & $\mathrm{~A}$ \\
Ambient temperature & 298 & $\mathrm{~K}$ \\
Desired stack temperature & 358 & $\mathrm{~K}$ \\
Exit stack temperature & 363 & $\mathrm{~K}$ \\
Ambient pressure & 1.0 & $\mathrm{bar}$ \\
Max Stack pressure & 4.0 & $\mathrm{bar}$ \\
RH entering compressor & 0.5 & \\
RH entering stack & 0.9 & \\
RH of hydrogen gas & 1.0 & \\
\hline
\end{tabular}


The system is designed to work on these input parameters and the optimum fuel cell working parameter values are obtained by matrix calculation illustrated below in Table 3 . The program worked by inserting different values from a given range and finding out the best exact value to get the highest overall performance of the stack.

According to the particular application requirements of the FCV, the turbocharger, the compressor and the electric centrifugal turbocharger are clear advantages in size, weight, ratio of pressure, noise and pressure fluctuations shown in Table 4. With the expander, the turbocharger and the electric turbocharger can reduce the power requirements of the scroll compressor. In addition, scroll compressor, screw compressor and rotary piston have better performance at high temperature (efficiency).

The centrifugal compressor was chosen because it has a greater efficiency, a compact size and therefore a low cost, less vibration and low noise and without oil mist, which is also one of the main causes of degradation of the FC. The above weighting and rating matrix also showing that the turbo compressor is better choice because it has a score of 1.868 i.e. $58.3 \%$ of the total score which is much higher compared to the twin-screw compressor.

Table 3 Weighting matrix

\begin{tabular}{lccccccll}
\hline Factor & A & B & C & D & E & F & Total & Weight \\
\hline A & & 1 & 1 & 0 & 1 & 1 & 4 & 0.267 \\
B & 0 & & 1 & 0 & 1 & 1 & 3 & 0.2 \\
C & 0 & 0 & & 0 & 1 & 0 & 1 & 0.067 \\
D & 1 & 1 & 1 & & 1 & 1 & 5 & 0.333 \\
E & 0 & 0 & 0 & 0 & & 1 & 1 & 0.067 \\
F & 0 & 0 & 1 & 0 & 0 & & 1 & 0.067 \\
& & & & & & $\Sigma$ & 15 & 1 \\
\hline
\end{tabular}

A - Efficiency; B - Cost; C - Vibration;

D - Mass limitation; E - Complexity; F - Safety

Table 4 Rating matrix

\begin{tabular}{llllll}
\hline Factor & Weight & \multicolumn{2}{c}{ Concept } & \multicolumn{2}{c}{ Weighting and rating } \\
& & I & II & I & II \\
\hline Efficiency & 0.267 & 2 & 2 & 0.534 & 0.534 \\
Cost & 0.2 & 1 & 2 & 0.2 & 0.4 \\
Vibration & 0.067 & 1 & 2 & 0.067 & 0.134 \\
Mass & 0.333 & 1 & 2 & 0.333 & 0.666 \\
limitation & 0.067 & 2 & 1 & 0.134 & 0.067 \\
Complexity & 0.067 & 1 & 1 & 0.067 & 0.067 \\
Safety & & & $\Sigma$ & 1.335 & 1.868 \\
& & & & &
\end{tabular}

I - Twin Screw Compressor; II - Turbo Compressor;

0- No match; 1-Partial match; 2-Full match.

\subsection{System performance}

Figure 4 shows the relationship between the current and system efficiencies. The graph shows two curves decreasing exponentially which tell that both the factors are inversely related to each other. As the current increases, the system efficiency decreases and vice-versa. However, there is an exception for the current range of 5 to $30 \mathrm{~A}$, during this period the relationship is linear. The maximum efficiency of the system was also observed during this period i.e. at $30 \mathrm{~A}$, which is $62.4 \%$ for both with and without expander. The minimum system efficiency with expander and without expander are $49.6 \%$ and $47.5 \%$ respectively which were recorded at the upper limit of the current.

Figure 5 shows the relationship between the current and the FCS voltage also known as the polarization curve. The graph shows a curve decreasing exponentially which shows inverse relationship between both the variables. When current rises, stack voltage drops and vice versa. The values for maximum and minimum voltages are $306.90 \mathrm{~V}$ and $259.05 \mathrm{~V}$ respectively, corresponding to the lower and upper limits of the current.

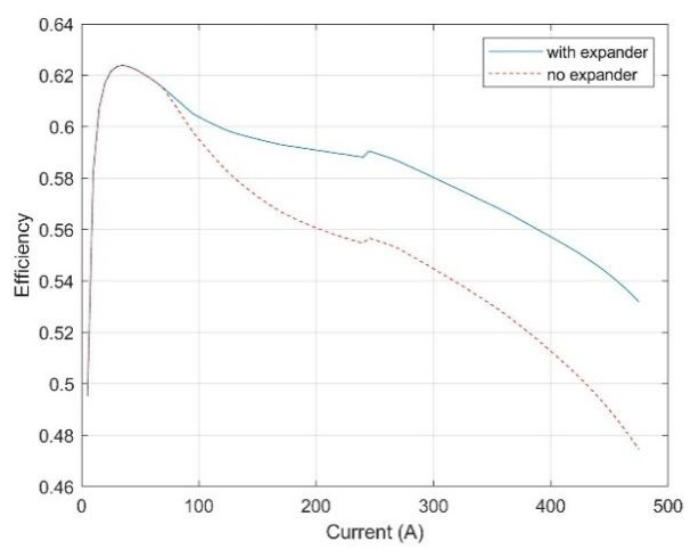

Fig. 4 System efficiencies with and without expander

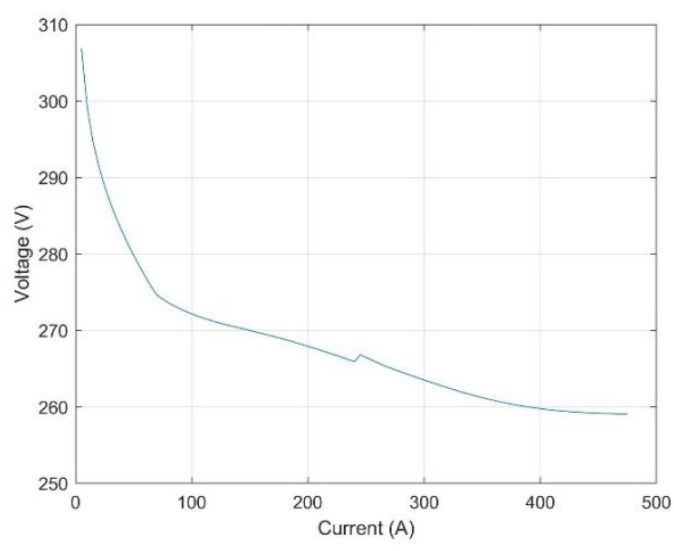

Fig. 5 Fuel cell system voltage 


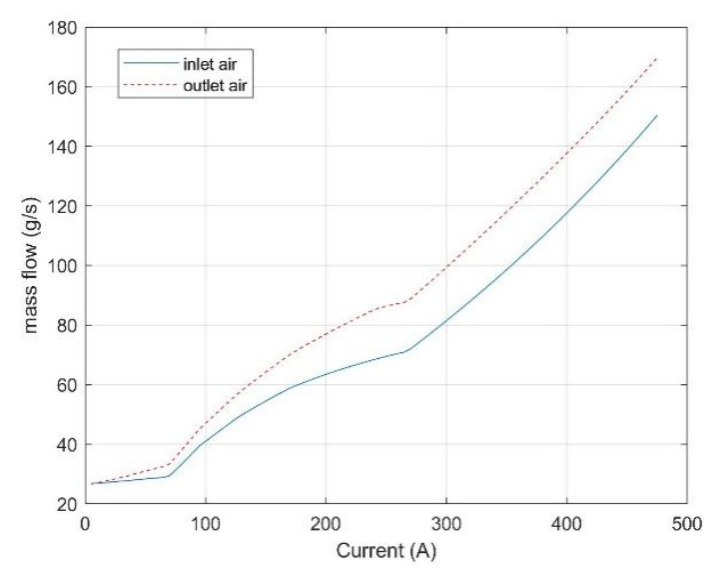

Fig. 6 Mass flow rates at FCS inlet and outlet

Figure 6 shows the relationship between the current and air mass flow rate. The graph shows two curves increasing exponentially which tell that both the factors are directly related to each other. As the current increases the air mass flow rate also increases and vice-versa. The minimum mass flow rates recorded of both inlet air and outlet air is $27.3 \mathrm{~g} / \mathrm{s}$ at the lower current and the maximum mass flow rates of inlet and outlet air recorded are $150.2 \mathrm{~g} / \mathrm{s}$ and $168.5 \mathrm{~g} / \mathrm{s}$ respectively at the upper limit of current.

\subsection{Compressor performance}

Figure 7 shows the relationship between the current and power required by compressor. The graph shows a curve increasing exponentially which tells that both the factors are directly related to each other. As the current increases, the power required by compressor also increases and vice-versa. The maximum power required by compressor is $24.8 \mathrm{~kW}$ at the upper limit of current.

Figure 8 shows the relationship between the current and temperature rise in compressor. The graph shows a curve

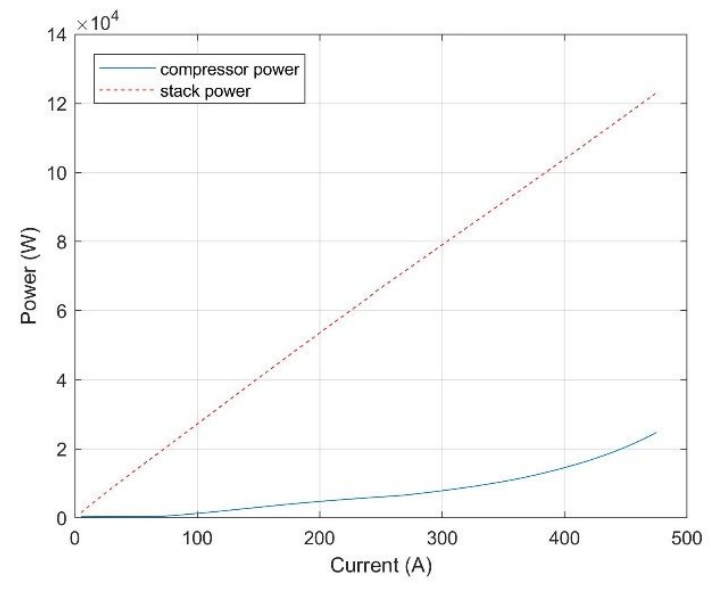

Fig. 7 Power consumed by compressor and stack

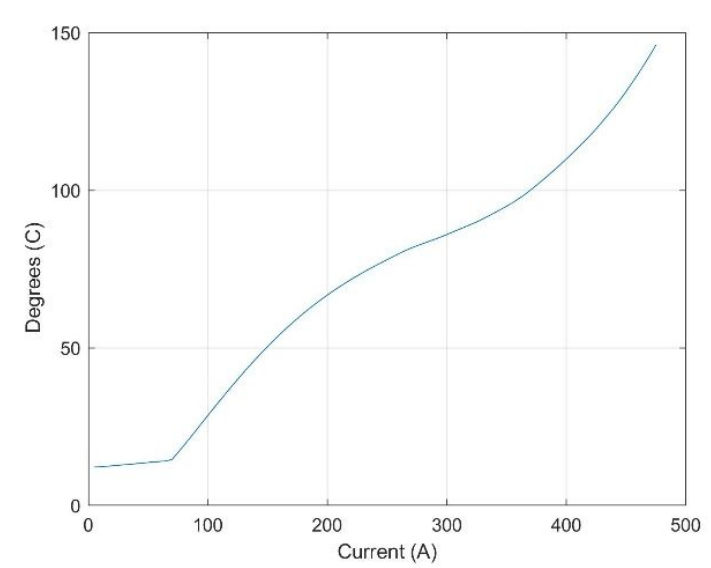

Fig. 8 Temperature rise inside compressor

increasing exponentially which tells that both the factors are directly related to each other. As the current increases, the temperature rise in compressor also increases and vice-versa. The minimum temperature rise recorded is $12.2^{\circ} \mathrm{C}$ at the lower limit of current and maximum temperature rise recorded is $146.1^{\circ} \mathrm{C}$ at the upper limit of current.

Figure 9 shows the relationship between the current and output pressure of compressor. The graph shows a curve increasing exponentially which tells that both the factors are directly related to each other. As the current increases, the output pressure of compressor also increases and vice-versa. The minimum output pressure recorded is 2.96 bar at the lower limit of current and maximum output pressure recorded is 1.1 bar at the upper limit of current.

Figure 10 shows the relationship between the current and adiabatic efficiency of compressor. The graph shows an unpredictable pattern, initially the adiabatic efficiency is approximately constant at $78.1 \%$ for the increase in

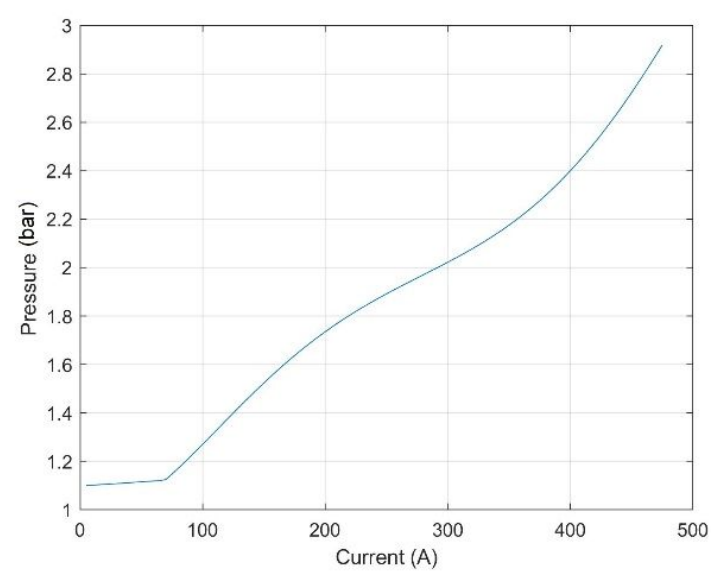

Fig. 9 Pressure rise inside compressor 


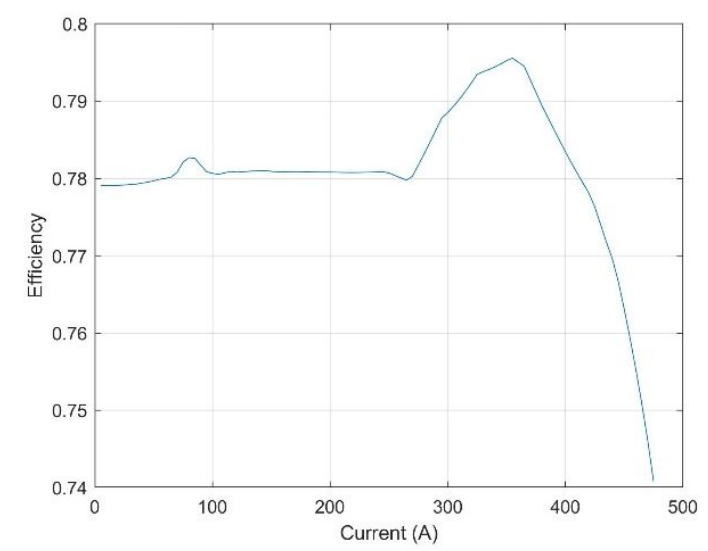

Fig. 10 Adiabatic efficiency of compressor

current then a slight peak is observed in adiabatic efficiency for a current value of 70 to $80 \mathrm{~A}$. After the small peak, again a straight line was observed till $270 \mathrm{~A}$, and then a sudden increase in adiabatic efficiency was observed to a maximum value of $79.6 \%$ corresponding at 360 A of current. After that the adiabatic efficiency decreases suddenly to a minimum value of $74.1 \%$ at the upper limit of the current.

The model developed to depict the performance of fuel cell system with a turbo compressor shows the results in the form of graphical representation. The most important graph which shows the performance of fuel cell system is the known as the polarization curve. However, in this model Figure 5 shows the polarization curve of the system and Figure 2 shows the typical polarization curve. It is quite obvious that both the figures have similar trends which prove that the model is correct. Whereas, other results such as system powers and compressor outputs are also in alignment with the published literature (Kulp, 2001; Pukrushpan, 2003; Wan et al., 2017).

\section{Conclusions}

The paper presents a performance analysis of the turbo compressor for efficient air management of PEMFC system incorporated in automotive applications. For system performance, the overall fuel cell system has higher efficiency for higher current loads with an expander. The air mass flow rate increases with the increased current load, however, the outlet air mass flow rate is higher compared to inlet air mass flow rate this is mainly due to higher absolute humidity of outlet air. For compressor performance, as the current load increases the required power of compressor also increases. Similarly, for higher loads the compressor does more work as a result, final temperature and pressure of the air increases. For this system the turbo compressor is designed to have a maximum efficiency at a value of $360 \mathrm{~A}$ current load which corresponds to the 3/4th (i.e. $75.8 \%$ ) of the peak load. The paper is quite useful to evaluate the performance of the turbo compressors used in fuel cell systems.

\section{Disclosures \\ Free Access to this article is sponsored by EURL BADYLEC.}

\section{References}

Ahsan, N., Mushtaq, K., Zaidi, A.A., 2019. Numerically simulated performance assessment for integration of PEM Fuel Cell Stack into an automobile, in: Book of Abstracts. p. 26.

Akinyele, D., Olabode, E., Amole, A., 2020. Review of Fuel Cell Technologies and Applications for Sustainable Microgrid Systems. Inventions 5, 42.

Al-Baghdadi, M., 2017. Proton exchange membrane fuel cells modeling: A review of the last ten years results of the Fuel Cell Research Center-IEEF 8.

Bethoux, O., 2020. Hydrogen Fuel Cell Road Vehicles and Their Infrastructure: An Option towards an Environmentally Friendly Energy Transition. Energies doi:10.3390/en13226132

Faiz Ahmed, S., Mushtaq, K., Ali, A., 2016. Design and performance analysis of floating dome type portable biogas plant for domestic use in Pakistan-manufacturing cost optimization. Biotechnology 15, 112-118. doi:10.3923/biotech.2016.112.118

Ganesan, V., 2010. Gas Turbines 3E. Tata McGraw-Hill Education.

Gimba, I.D., Abdulkareem, A.S., Jimoh, A., Afolabi, A.S., 2016. Theoretical Energy and Exergy Analyses of Proton Exchange Membrane Fuel Cell by Computer Simulation. J. Appl. Chem. 2016, 2684919. doi:10.1155/2016/2684919

Hoogers, G., 2002. Fuel cell technology handbook. CRC press

Kulp, G.W., 2001. A comparison of two air compressors for PEM fuel cell systems, Virginia Tech.

Malik, A., Qureshi, S.R., Abbas, N., Zaidi, A.A., 2020. Energy and exergy analyses of a solar desalination plant for Karachi Pakistan. Sustain. Energy Technol. Assessments 37, 100596. doi:https://doi.org/10.1016/j.seta.2019.100596

Mehdi, G., Ali, N., Hussain, S., Zaidi, A.A., Shah, A.H., Azeem, M.M., 2019. Design and Fabrication of Automatic Single Axis Solar Tracker for Solar Panel, in: 2019 2nd International Conference on Computing, Mathematics and Engineering Technologies (ICoMET). pp. 1-4. doi:10.1109/ICOMET.2019.8673496

Mondial, C., Gie, D.E.L.É., Gadonneix, P., Kim, Y.D., Meyers, K., Ward, G., Frei, C., 2013. World Energy Resources 2013. World Energy Council, London.

Mushtaq, K., Zaidi, A.A., Askari, S.J., 2016. Design and performance analysis of floating dome type portable 
biogas plant for domestic use in Pakistan. Sustain. Energy Technol. Assessments 14, 21-25. doi:10.1016/j.seta.2016.01.001

Pakle, S., Jiang, K., 2018. Design of a high-performance centrifugal compressor with new surge margin improvement technique for high speed turbomachinery. Propuls. Power Res. 7, 19-29. doi:https://doi.org/10.1016/j.jppr.2018.02.004

Pischinger, S., Schönfelder, C., Bornscheuer, W., Kindl, H., Wiartalla, A., 2001. Integrated air supply and humidification concepts for fuel cell systems. SAE Trans. 86-92.

Pukrushpan, J.T., 2003. Modeling and control of fuel cell systems and fuel processors, University of Michigan Ann Arbor, Michigan, USA.

Robison, D.H., Beaty, P.J., 1992. Compressor Types, Classifications, And Applications., in: Proceedings of the 21st Turbomachinery Symposium. Texas A\&M University. Turbomachinery Laboratories.

Shamim, S., Sudhakar, K., Choudhary, B., Anwar, J., 2015. A review on recent advances in proton exchange membrane fuel cells: materials, technology and applications. Adv. Appl. Sci. Res. 6, 89-100.
Sugawara, T., Kanazawa, T., Tachibana, Y., Imai, N., 2016. Development of air supply system for Clarity fuel cell, Honda R\&D Tech. Rev. 28.

Wan, Y., Guan, J., Xu, S., 2017. Improved empirical parameters design method for centrifugal compressor in PEM fuel cell vehicle application. Int. J. Hydrogen Energy 42, 5590-5605. doi:https://doi.org/10.1016/j.ijhydene.2016.08.162

Weyers, C., Bocklisch, T., 2018. Simulation-based investigation of energy management concepts for fuel cell - battery hybrid energy storage systems in mobile applications. Energy Procedia 155, 295-308. doi:https://doi.org/10.1016/j.egypro.2018.11.048

Wilberforce, T., Olabi, A.G., 2020. Performance prediction of proton exchange membrane fuel cells (PEMFC) using adaptive neuro inference system (ANFIS). Sustainability 12, 4952.

Yu, W., Sichuan, X., Ni, H., 2015. Air Compressors for Fuel Cell Vehicles. SAE Int. J. Altern. Powertrains 4, 115-122.

Zhao, D., Daniel, K., Blunier, B., Zwyssig, C., Dou, M., Miraoui, A., 2012. Design and control of an ultra high speed turbo compressor for the Air Management of fuel cell systems, in: 2012 IEEE Transportation Electrification Conference and Expo (ITEC). pp. 1-6. doi:10.1109/ITEC.2012.6243438 